Rheum Dis, 16(4), 494-502.

4. Fraser J.R.E., Laurent T.C., và Laurent U.B.G. (1997). Hyaluronan: its nature, distribution, functions and turnover. Journal of Internal Medicine, 242(1), 27-33.

5. "The use of hyalodronic acid in chondral diorders of the knee" 2014Author: Dr.I.Capparucci, Dr.C.Bartolucci, Prof.A.Federici, Prof.ass Valentini, Dott.V.VitaDepartment of
Biological Science, Faculty of Sport Medicine, University of Urbino, Italy.

6. N. V. Pho (2007). Đánh giá hiệu quả của tiêm chất nhây sodium-hyaluronate ( Go-on ) vào ổ khớp trong điều trị thoái hóa khóp gối. Luận văn tốt nghiệp bác sĩ chuyên khoa II.

7. Pham Thi Bích Ngoc (2019) Đánh giá tác dung điêu tri của liêu pháp tiêm nôi khớp bằng acid hyaluronic (Regenflex Bio-Plus) trong điều trị thoái hóa khớp gối nguyên phát.

\title{
MỐI LIÊN QUAN GIỮA BIẾN THỂ ADIPOQ rs1501299 VÀ BÊNNH ĐÁI THÁO ĐƯỜNG TÍP 2 Ở NGƯỜI VIÊTT NAM
}

\author{
Trần Quang Nam ${ }^{1}$, Steven Truong ${ }^{2}$, Hoàng Khánh $\mathrm{Chi}^{3}$, \\ Lê Hoàng Bảo ${ }^{3}$, Đinh Ngô Tất Thắng ${ }^{3}$, Trần Viết Thắng ${ }^{1}$, \\ Trần Văn Lượng ${ }^{3}$, Mã Tùng Phát ${ }^{1}$, Mai Phương Thảo ${ }^{1}$, Đỗ Đức Minh ${ }^{1}$
}

\section{TÓM TẮT}

Mục tiêu: Yếu tố di truyền đóng vai trò quan trọng trong sinh bệnh học của bệnh lý đái tháo đường. Trong nghiên cứu này, chúng tôi khảo sát mối liên quan giữa đểm đa hình đơn nucleotide rs1501299 ADIPOQ và bệnh lý đái tháo đường típ 2 ở người Việt Nam. Đối tượng và phương pháp: Thiết kế nghiên cứu cắt ngang mô tả, 376 bệnh nhân đái tháo đường típ 2 và 392 đối tượng chứng được khảo sát điểm đa hình đơn rs1501299 bằng phương pháp realtime PCR. Kết quả: Điểm đa hình rs1501299 không cho thấy có sư liên quan với tình trang bênh đái tháo đường típ 2 ở người Việt Nam trên nhiêu mô hình phân tích. Người mang điểm đa hình này không gia tăng nguy cơ mắc đái tháo đường típ 2. Kết luận: Điểm đa hình đơn rs1501299 không liên quan với tình trạng đái tháo đường típ 2 ở người Việt Nam.

Tư khóa: đái tháo đường típ 2, điểm đa hình đơn nucleotide, gen ADIPOQ

\section{SUMMARY}

\section{THE ASSOCIATION BETWEEN ADIPOQ rS1501299 AND TYPE 2 DIABETES IN VIETNAMESE POPULATION}

Background: Genetic factor plays an important role in pathophysiology of type 2 diabetes. In this study, we evaluated the association between ADIPOQ rs1501299 and type 2 diabetes in Vietnamese population. Objectives and methods: In this cross sectional study, 376 type 2 diabetic patients and 392 controls were recruited and genotyped for ADIPOQ rs1501299 by real-time PCR. Results: ADIPOQ rs1501299 was not statistically associated with type 2

${ }^{1}$ Đai hoc Y Dướ TPHCM

${ }^{2}$ Khoa Kỹ thuât Sinh học, Viện Công nghệ Massachusetts ${ }^{3}$ Bênh viên Đai hoc Y Dước TPHCM

Chịu trách nhiệm chính: Đố Đức Minh

Email: ducminh@ump.edu.vn

Ngày nhận bài: 23.6.2021

Ngày phản biên khoa hoc: 20.8.2021

Ngày duyệt bài: 27.8.2021 diabetes in Vietnamese population by different statistical models. The rs1501299 carriers do not increase the risk of developing type 2 diabetes. Conclusion: ADIPOQ rs1501299 is not associated with type 2 diabetes mellitus in Vietnamese population.

Keywords: type 2 diabetes mellitus, single nucleotide polymorphism, ADIPOQ gene

\section{I. ĐĂT VẤN ĐỀ}

Đái tháo đường típ 2 hiên được xem là môt trong những bệnh lý không lây nhiễm phổ biển nhất và là gánh nặng y tế của nhiều quốc gia trên thế giới, trong đó số lượng bênh nhân chưa được chẩn đoán chiếm gần môt nửa ${ }^{(1,2)}$. Bên cạnh các yếu tố môi trường, yếu tố di truyền đóng vai trò hết sức quan trọng trong sinh bệnh hoc của đái tháo đường típ 2. Các nghiên cứu gẩn đây cho thấy bênh nhân đái tháo đường típ 2 người châu Á thường có kiểu hình suy giảm chức năng tế bào beta tuy nổi trội hơn là tình trang đề kháng insulin ${ }^{(3)}$.

Adiponectin được mã hóa từ gen $\mathrm{ADIPOQ}$ nằm trên nhiễm sắc thể số 3 , được xem là một loại hormone chế tiết từ tế bào mỡ tham gia vào quá trình chuyển hoá đường và chất béo trong cơ thể. Các nghiên cứu gần đây cho thây nồng độ adiponectin thấp có liên quan đến nguy cơ xuất hiên đái tháo đường típ 2 ở cả người da trắng và châu Á ${ }^{(4,5)}$. Một số biến thể đa hình đơn nucleotide trên gen $A D I P O Q$ cho thấy có thể làm ảnh hưởng đến nồng độ adiponectin của các đối tượng tham gia nghiên cứu mà cư thể là có liên quan với tình trạng giảm thấp có ý nghĩa thống kê nồng độ adiponectin và do đó có thể liên quan mật thiết với nguy cơ mắc bệnh đái tháo đường típ $2^{(6)}$. Trong số các biến thể gen này, rs1501299 đã được chứng minh có liên quan 
chặt chẽ với bệnh lý đái tháo đường típ 2 trên dân số người Châu $A^{(7,8)}$. Do đó, chúng tôi tiến hành nghiên cứu này nhằm khảo sát mối liên quan giữa biến thể gen ADIPOQ rs1501299 và bệnh lý đái tháo đường típ 2 tại Việt Nam.

\section{II. ĐỐI TƯợNG VÀ PHƯƠNG PHÁP NGHIÊN CỨU}

1. Đối tượng nghiên cứu: Các đối tượng được chọn tham gia vào nghiên cứu ở 2 nhóm là nhóm bểnh nhân đái tháo đường típ 2 và nhóm chứng với các tiêu chuẩn cụ thể như sau:

\section{Nhóm đái tháo đường típ 2:}

Tiêu chuẩn chon mấu:

- Bệnh nhân thỏa tiêu chuẩn chẩn đoán đái tháo đường típ 2 theo tiêu chuẩn của Hiệp hội đái tháo đường Hoa Kỳ 2020(9)

Tiêu chuẩn loại trừ

- Bênh nhân đái tháo đường típ 1

- Rối loạn chức năng gan

- Sử dụng các thuốc có khả năng làm tăng đường huyết

- Bệnh nhân không đồng ý tham gia nghiên cứu

\section{Nhóm chứng:}

Tiêu chuẩn chọn mẫu:

- Chưa từng được chẩn đoán đái tháo đường

- Đường huyết đo được tại thời điểm hiện tại $<100 \mathrm{mg} / \mathrm{dL}$

- Bệnh nhân đồng ý tham gia nghiên cứu

Tiêu chuẩn loai trừ:

- Sử dụng thuốc hoặc có các bệnh lý có thể ảnh hưởng đến đường huyết

\section{Phương pháp nghiên cứu}

2.1 Thiết kế nghiên cứu: bệnh chứng

\section{KẾT QUẢ NGHIÊN CỨU}

1. Đăc điểm của dân số nghiên cứu. Nhóm bênh nhân đái tháo đường típ 2 và nhóm chứng có sự khác biệt có ý nghĩa thống kê giữa các trị số như tuổi, chỉ số khối cơ thể (BMI), tỉ lệ vòng eo-hông, đường huyết đói và các thông số lipid máu $(p<0.05)$.

\begin{tabular}{|c|c|c|c|}
\hline & Đái tháo đường & Chứng & Trị số $\mathbf{P}$ \\
\hline Tống số & 376 & 392 & \\
\hline Nam/nữ & $150 / 226$ & $159 / 233$ & $0.908^{*}$ \\
\hline Thời gian đái tháo đường (năm) & $5.71 \pm 6.00$ & 0 & \\
\hline Tuối (năm) & $55.07 \pm 11.90$ & $45.56 \pm 12.64$ & $<0.0001$ \\
\hline BMI (kg/m²) & $24.84 \pm 3.59$ & $23.21 \pm 3.38$ & $<0.0001$ \\
\hline Chỉ số eo-hông & $0.92 \pm 0.07$ & $0.89 \pm 0.07$ & $<0.0001$ \\
\hline HbA1c (\%) & $8.25 \pm 2.10$ & $5.69 \pm 0.47$ & $<0.0001$ \\
\hline Đường huyết đói (mmol/L) & $8.59 \pm 3.05$ & $5.52 \pm 0.90$ & $<0.0001$ \\
\hline HA tâm thu (mmHg) & $130.77 \pm 17.93$ & $126.2 \pm 16.3$ & $<0.001$ \\
\hline HA tâm trương (mmHg) & $78.2 \pm 10.7$ & $80.0 \pm 11.1$ & 0.188 \\
\hline Triglycerides $(\mathrm{mmol} / \mathrm{L})$ & $2.48 \pm 1.93$ & $2.05 \pm 2.05$ & $<0.01$ \\
\hline Cholesterol $(\mathrm{mmol} / \mathrm{L})$ & $4.72 \pm 1.44$ & $5.37 \pm 1.33$ & $<0.0001$ \\
\hline HDL-cholesterol $(\mathrm{mmol} / \mathrm{L})$ & $1.12 \pm 0.28$ & $1.27 \pm 0.44$ & $<0.0001$ \\
\hline LDL-cholesterol $(\mathrm{mmol} / \mathrm{L})$ & $2.97 \pm 1.06$ & $3.48 \pm 0.89$ & $<0.0001$ \\
\hline Creatinine $(\mathrm{mg} / \mathrm{dL})$ & $0.87 \pm 0.24$ & $0.88 \pm 0.54$ & 0.895 \\
\hline
\end{tabular}

2.2 Cõ̃ mẫu: 768 đối tượng bao gồm 376 bệnh nhân đái tháo đường típ 2 và 392 đối tượng chứng

2.3 Phương pháp thực hiện. Tất cả các đối tượng tham gia nghiên cứu sẽ được thu thập đầy đủ các thông tin lâm sàng và cận lâm sàng liên quan đến bệnh lý đái tháo đường típ 2 . Mỗi bệnh nhân sẽ đước thu thâp $2 \mathrm{ml}$ máu ngoai biên để xác đinh điểm đa hình rs1501299. DNA từ máu ngoại biên sẽ được tách chiết sử dụng bộ kit QiAmp DNA Blood Mini Kit (QIAGEN, Đức). Điểm đa hình rs1501299 sẽ được xác định bằng kỹ thuât realtime PCR với bộ mồi Tagman (Thermo Fisher Scientific, Waltham, MA, Hoa Kỳ) được thiết kế sẵn cho điểm đa hình này. Phản ứng PCR được thực hiện với $5 \mu \mathrm{L}$ dung dich có chứa DNA hòa tan trong dung dịch Tris-EDTA pH 8.0, TaqMan Genotyping Master Mix và bộ mồi.

2.4 Phân tích thống kê: T-test và $X 2$ test được sử dụng lần lượt cho các biến định lượng và định tính. Phần mềm SNPstats được sử dụng để đánh giá mối liên quan giữa điểm đa hình rs1501299 và tình trạng đái tháo đường típ 2 theo các mô hình di truyền: đồng trôii, trội, lặn ${ }^{(10)}$. Khác biệt được xem là có ý nghĩa thống kê khi trị số $p \leq 0,05$

2.5 Vấn đề đạo đức trong nghiên cứu: Đề tài nghiên cứu đã̃ được sự chấp thuận của Hội đồng đạo đức trong nghiên cứu $Y$ sinh học Đại học Y Dược Thành phố Hồ Chí Minh với quyết định số 350/HĐĐĐ-ĐHYD ngày 26 tháng 5 năm 2020 và được tài trợ bởi quỹ Nafosted (mã số tài trợ 108.01-2019.319). 


\section{Mối liên quan giữa biến thể rs1501299 và đái tháo đường típ 2}

Phân bố của biến thể gen rs1501299 tuân theo định luật cân bằng di truyền Hardy-Weinberg $(p>$ 0.05). Các mô hình di truyền được phân tích bao gồm đồng trội, trội, lặn. Tỉ số chênh $(O R)$ được tính toán với $95 \%$ khoảng tin cậy (KTC). Bên cạnh kết quả OR nguyên bản, chỉ số OR này còn được hiệu chỉnh theo các biến số như tuổi, giới và BMI.

\begin{tabular}{|c|c|c|c|c|c|c|c|}
\hline $\begin{array}{c}\text { Rs150 } \\
1299 \\
\end{array}$ & $\begin{array}{l}\text { Kiếu } \\
\text { gen }\end{array}$ & $\begin{array}{c}\text { Chứng } \\
\text { (n) }\end{array}$ & $\begin{array}{l}\text { Đái tháo } \\
\text { đường(n) }\end{array}$ & $\begin{array}{c}\text { OR (95\% } \\
\text { KTC) }\end{array}$ & $\mathbf{P}$ & $\begin{array}{l}\text { OR hiệu chỉnh } \\
\text { (95\% KTC) }\end{array}$ & $\begin{array}{l}\text { P hiệu } \\
\text { chỉnh }\end{array}$ \\
\hline \multirow{3}{*}{$\begin{array}{l}\text { Đồng } \\
\text { trội }\end{array}$} & $\mathrm{G} / \mathrm{G}$ & 210 & 184 & 1 & \multirow{3}{*}{0,41} & 1 & \multirow{3}{*}{0,2} \\
\hline & $\mathrm{G} / \mathrm{T}$ & 156 & 162 & $1,19(0,88-1,59)$ & & $1,34(0,97-1,86)$ & \\
\hline & $\mathrm{T} / \mathrm{T}$ & 26 & 30 & $1,32(0,75-2,31)$ & & $1,05(0,57-1,93)$ & \\
\hline \multirow[b]{2}{*}{ Trội } & $\mathrm{G} / \mathrm{G}$ & 210 & 184 & 1 & \multirow[b]{2}{*}{0,2} & 1 & \multirow{2}{*}{0,11} \\
\hline & $\mathrm{G} / \mathrm{T}, \mathrm{T} / \mathrm{T}$ & 182 & 192 & $1,20(0,91-1,60)$ & & $1,29(0,95-1,76)$ & \\
\hline \multirow{2}{*}{ Lặn } & $\mathrm{G} / \mathrm{G}, \mathrm{G} / \mathrm{T}$ & 366 & 346 & 1 & \multirow{2}{*}{0,47} & 1 & \multirow{2}{*}{0,79} \\
\hline & $\mathrm{T} / \mathrm{T}$ & 26 & 30 & $1,22(0,71-2,11)$ & & $0,92(0,51-1,67)$ & \\
\hline
\end{tabular}

Có thể thấy trong cả 3 mô hình phân tích, điếm đa hình rs1501299 hoàn toàn không có liên quan với bệnh lý đái tháo đường típ 2 có ý nghĩa thống kê với các chỉ số OR trước và sau hiệu chỉnh dao động quanh giá trị 1.

\section{BÀN LUÂN}

Các nghiên cứu trước đây cho thây mối liên quan giữa các đặc điểm di truyền và tình trạng bệnh lý cũng như đáp ứng thuốc ở người Việt Nam khá tương đồng với các dân số Châu Á lận cận. Tuy nhiên, trong nghiên cứu này, chúng tôi đã phát hiện điểm đa hình ADIPOQ rs1501299 hoàn toàn không có liên quan đến nguy cơ đái tháo đường típ 2 ở người Việt Nam. Kết quả này một lần nữa cho thấy dù có nhiều đặc điểm tương đồng nhưng dân số người Việt Nam vẫn có những đặc điểm di truyền đặc trưng riêng so với các dân số châu Á còn lại.

Một trong những hạn chế của nghiên cứu này là chúng tôi không đo nồng độ adiponectin máu. Việc khảo sát nồng độ adiponectin sẽ giúp xác định rõ hơn có hay không mối liên quan giữa biến thể rs1501299 với tình trạng đái tháo đường thông qua việc giảm nồng độ adiponectin máu. Các bằng chứng này sẽ làm rõ thêm ảnh hưởng của biến thể gen này trong sinh bệnh học của đái tháo đường típ 2 tại Việt Nam.

\section{KẾT LUẦN}

Không có mối liên hệ giữa biến thể rs1501299 và tình trạng đái tháo đường típ 2 tại Việt Nam. Cần có các nghiên cứu về mối liên quan giữa các điểm đa hình khác trên gen $A D I P O Q$ với tình trạng đái tháo đường típ 2 tại Việt Nam để chúng ta có thể hiểu biết rõ hớn về vai trò của gen ADIPOQ trong sinh bệnh học của bệnh lý này.

\section{TÀI LIỆU THAM KHẢO}

1. Ogurtsova $K$, Fernandes JD da $R$, Huang $Y$, et al. IDF Diabetes Atlas: Global estimates for the prevalence of diabetes for 2015 and 2040. Diabetes Res Clin Pract. 2017;128:40-50. doi:10.1016/j.diabres.2017.03.024
2. Phan HH, Lam HV, Le NT, et al. Prevalence and clinical profile of undiagnosed diabetes mellitus: data from a tertiary hospital. Endocr Metab Immune Disord Drug Targets. October 2020. doi:10.2174/1871530320666201014151408

3. Fukushima $\mathbf{M}$, Usami $\mathbf{M}$, Ikeda $\mathbf{M}$, et al. Insulin secretion and insulin sensitivity at different stages of glucose tolerance: a cross-sectional study of Japanese type 2 diabetes. Metabolism. 2004;53(7): 831-835. doi:10.1016/j.metabol.2004.02.012

4. Duncan BB, Schmidt MI, Pankow JS, et al. Adiponectin and the Development of Type 2 Diabetes: The Atherosclerosis Risk in Communities Study. Diabetes. 2004;53(9):2473-2478. doi:10.2337/diabetes.53.9.2473

5. Wang $\mathbf{Y}$, Meng R-W, Kunutsor SK, et al. Plasma adiponectin levels and type 2 diabetes risk: a nested case-control study in a Chinese population and an updated meta-analysis. Sci Rep. 2018;8. doi:10.1038/s41598-017-18709-9

6. Ong KL, Li M, Tso AWK, et al. Association of genetic variants in the adiponectin gene with adiponectin level and hypertension in Hong Kong Chinese. Eur J Endocrinol. 2010;163(2):251-257. doi:10.1530/EJE-10-0251

7. Tsai M-K, Wang H-MD, Shiang J-C, et al. Sequence Variants of ADIPOQ and Association with Type 2 Diabetes Mellitus in Taiwan Chinese Han Population. Sci World J. 2014;2014:e650393. doi:10.1155/2014/650393

8. Cui $M$, Gao $Y$, Zhao $\mathbf{Y}$, et al. Association between Adiponectin Gene Polymorphism and Environmental Risk Factors of Type 2 Diabetes Mellitus among the Chinese Population in Hohhot. BioMed Res Int. 2020;2020:e6383906. doi:10.1155/2020/6383906

9. American Diabetes Association. 2 Classification and Diagnosis of Diabetes: Standards of Medical Care in Diabetes-2020. Diabetes Care. 2020;43(Suppl 1):S14-S31. doi:10.2337/dc20-S002

10. Solé $X$, Guinó $E$, Valls J, Iniesta $R$, Moreno V. SNPStats: a web tool for the analysis of association studies. Bioinforma Oxf Engl. 2006:22(15):1928-1929. bioinformatics/ bt1268 